\title{
A influência da composição do esteatito (pedra-sabão) na migração de minerais para os alimentos - Minerais do esteatito
}

\author{
(The influence of the steatite (soapstone) composition in mineral \\ migration to food meal - Minerals from steatite)
}

\author{
K. D. Quintaes \\ Hospital Heliópolis, Unidade Geral Assistencial I \\ R. Cônego Xavier, 276, $10^{\circ}$ andar, S. Paulo, SP 04231-030 \\ fone/fax: 11-22738224.
}

\begin{abstract}
Resumo
O esteatito, rocha metamórfica composta por talco, dolomita e anfibólios, é abundantemente encontrado no Quadrilátero Ferrífero brasileiro, em Minas Gerais. O esteatito tem aplicação industrial, sendo também usado na confecção de esculturas e utensílios culinários, conhecidos como panelas de pedra-sabão. A tradição na aplicação culinária das panelas de pedra-sabão ainda se mantém ativa. Cerca de $80 \%$ da população nativa de Ouro Preto (MG, Brasil) possui as referidas panelas, sendo que estas são usadas no preparo de alimentos por $63 \%$ dos seus habitantes. A sabedoria popular indica que seu uso auxilia no tratamento e prevenção da anemia ferropriva. Porém, mesmo sendo o esteatito um dos primeiros materiais usados pelo homem na fabricação de utensílios para contato com alimentos, o respaldo acadêmico sobre sua interação com alimentos é recente e pontual. Pela ausência de dados, os primeiros testes feitos usaram simulantes de alimentos a fim de predizer o comportamento do material nas condições domésticas de uso: cocção e estocagem de alimentos. A migração de metais como ferro, cálcio, magnésio e manganês, além de níquel, foi constatada nestes estudos. Todavia, a migração dos metais durante a vida útil do recipiente continua desconhecida. Ampliar o conhecimento sobre a implicação nutricional dos utensílios culinários de pedra-sabão ainda se faz necessário pela escassez de dados sobre o comportamento deste material. O presente artigo visa, mediante a revisão da literatura, apresentar à comunidade científica os dados disponíveis sobre a composição do esteatito (pedra-sabão) e sua influência no contato com alimentos e na saúde humana.
\end{abstract}

Palavras-chave: dolomita, migração, utensílios culinários, toxicologia, níquel.

\begin{abstract}
Steatite is a metamorphic rock composed mainly of minerals talc, dolomite and amphibolites. It is abundantly found in the Southeast of Brazil especially in the state of Minas Gerais. In addition to its industrial use, it has also been used for manufacture of sculptures and cooking utensils, called "soapstone cookware". The tradition of food preparation using soapstone cookware is alive among in habitants of Ouro Preto (MG, Brazil), where 80\% of the native population has this utensil and $63 \%$ of them use it in food preparation. The common knowledge shows that it can be used to treat and prevent iron anemia. Although steatite was found to be one of the first materials used by man in the manufacture of cooking utensils, the scientific knowledge of its interaction with food is limited. Due to lack of data, tests were made with food simulants in order to predict its behavior in domestic use, as cookware and food container, in which was observe the migration of metals such as iron, calcium, manganese, magnesium and nickel. However, the metals migration of during the shelf life of the cookware continues unknown. More studies about nutritional implication of soapstone cookware still necessary. The scientific information about the behavior of this material is limited. The aim of this paper was to provide to the scientific community the recent review of the information about steatite composition and its influence in food contact and human health.
\end{abstract}

Keywords: dolomite, migration, food utensils, toxicology, nickel.

\section{INTRODUÇÃO}

É remoto o tempo em que o homem começou a buscar na natureza o material mais apropriado para a confecção de recipientes culinários [1,2]. Este material, além de estar disponível no seu habitat, deveria ser resistente ao fogo e ainda conferir ou mesmo melhorar as características sensoriais dos alimentos, tais como maciez, aroma e sabor [2].

Estima-se que há 2.000.000 anos o homem pré- 
histórico usava fragmentos de pedra e de madeira recolhidos do meio ambiente como instrumentos para sobreviver e conseguir seu alimento. Possivelmente o primeiro material usado como recipiente culinário foi à pedra esculpida na forma de utensílio, seguida da cerâmica [1-3]. O esteatito, rocha que devido à pequena dureza tem sido empregada na confecção de artefatos, foi provavelmente uma das primeiras matérias primas usada para produção de recipientes com propósitos culinários [2]. Posteriormente, com a descoberta do fogo, o aquecimento e a defumação puderam ser adotados pelo homem como recursos para alterações das propriedades dos alimentos. O aquecimento casual dos alimentos sobre materiais como areia e argila promoveu a conversão destes a outra forma física [2-4].

Entretanto, a preocupação com a necessidade de melhorar as características sensoriais e sanitárias dos alimentos bem como praticidade, beleza, disponibilidade do material e inocuidade contribuíram para a busca por novos materiais. Assim, diversas têm sido as matériasprimas empregadas, tanto artesanal como industrialmente, na confecção dos utensílios culinários. Nesta busca pelo material ideal, ficou constatado que não existe apenas um material, e sim vários, dependendo da disponibilidade geográfica, do tipo do alimento e da preparação a ser efetuada $[1,5]$.

Aliteratura relata que utensílios culinários de diferentes materiais estão associados a migrações específicas para a comida [5]. Há mais de meio século é conhecido que o alumínio (Al) migra de panelas produzidas com este material, durante a preparação e estocagem de alimentos [5-7]. Já materiais como o ferro fundido e aço inoxidável (inox) são considerados como fontes de ferro [8-10], sendo que o inox pode liberar ainda cromo e níquel [9$11]$.

Assim, já é bastante notório que durante a elaboração culinária, interações entre os alimentos e os utensílios ocorrem. Algumas destas são benéficas à saúde do comensal, outras são inócuas, enquanto algumas podem ser consideradas prejudiciais. Apesar do esteatito ser um dos primeiros materiais usados na fabricação de utensílios para contato com alimentos [12], só recentemente o mesmo tem sido avaliado no que diz respeito à sua implicação nutricional [2, 10, 13, 14]. Desta forma, este artigo teve como objetivo, mediante a revisão da literatura, apresentar à comunidade científica os dados disponíveis sobre a composição do esteatito (pedrasabão) e sua influência no contato com alimentos e na saúde humana.

\section{Características físico-químicas do esteatito}

O esteatito é classificado geológicamente como sendo uma rocha metaultramáfica [12, 15-17]. As rochas metaultramáficas caracterizam-se por tipos petrográficos variados em função do grau de transformação metamórfica. Tipos completamente metamorfizados são carbonato- talco-serpentina, tremolitito, clorita xisto, serpentinito e esteatito [15]. A região do Quadrilátero Ferrífero brasileiro, localizado em Minas Gerais (Brasil), contém importantes e abundantes jazidas de esteatito $[16,17]$. As principais localidades com ocorrências de jazidas de esteatito são: Santa Rita de Ouro Preto, Viriato, Acaiaca, Congonhas do Campo, Cachoeira do Brumado e Ouro Branco, todas em Minas Gerais (Brasil) [17].

Esteatitos são usualmente formados por diversos minerais geológicos, entre os quais se destacam o talco $\mathrm{Mg}_{3} \mathrm{Si}_{4} \mathrm{O}_{10}(\mathrm{OH})_{2}$, a dolomita $\mathrm{CaMg}\left(\mathrm{CO}_{3}\right)$, a actinolita C $\mathrm{a}_{2}\left(\mathrm{Mg}_{2} \mathrm{Fe}^{2+}\right) \mathrm{Si}_{5} \mathrm{O}_{22}(\mathrm{OH})_{2}$, e a lorita $(\mathrm{Mg}, \mathrm{Al}, \mathrm{Fe})_{12}\left[(\mathrm{Si}, \mathrm{Al})_{8}\right.$ $\left.\mathrm{O}_{20}^{2}\right](\mathrm{OH})_{16}{ }^{5}$ Tambem são encontrados no esteatito alguns minerais acessórios como: pirita, $\mathrm{FeS}$; arsenopirita, FeAsS; magnetita, $\mathrm{Fe}^{2+} \mathrm{Fe}_{2}{ }^{3+} \mathrm{O}_{4}$; epidoto, $\mathrm{Ca}_{2}\left(\mathrm{Fe}^{3+}, \mathrm{Al}\right)_{3}(\mathrm{Si}$ $\left.\mathrm{O}_{4}\right)_{3}(\mathrm{OH})$; titanita, $\mathrm{CaTiSiO}_{5}[17-19]$. Cabe destacar que rochas ultramáficas, como o esteatito, e seus produtos são usualmente enriquecidos com elementos traço, como cromo, níquel e cobalto, se comparadas com outros tipos de rochas $[12,19]$. Os esteatitos das jazidas localizadas em Santa Rita de Ouro Preto são considerados de alta pureza, sendo compostos predominantemente por talco e pequenas quantidades de dolomita [17].

Durante o metamorfismo do esteatito, elementos podem ser incorporados aos minerais recristalizados, na maioria das vezes na forma de substituições. Pelos seus raios iônicos, valência e distribuição de carga, pequenas quantidades de níquel substituindo magnésio na serpentina; cromo na posição do titânio na titanita; cromo substituindo o ferro, e níquel ou cobalto no lugar do ferro na magnetita; níquel ou cobalto substituindo o ferro na pirita; e cromo, níquel e titânio em cloritas, podem ser observados. Considerando elementos majoritários, alumínio pode ser encontrado substituindo tanto silício quanto magnésio no talco. Trocas usuais incluem ferro e manganês em dolomitas, substituindo magnésio [19, 20].

Popularmente o esteatito ficou conhecido como talco, um dos seus minerais majoritários. A plasticidade do material, refletida na baixa dureza, característica marcante destas rochas, se deve especialmente à composição mineralógica apresentada. Entre os diversos tipos de rochas, o esteatito se destaca por possuir o menor grau na classificação da Escala de Dureza de Mohs, escala arbitrária onde os minerais são classificados conforme sua dureza relativa entre um e dez [21]. Essa característica permite que a rocha seja facilmente riscada, inclusive com a unha, garantindo seu emprego tanto na forma artesanal como industrial.

\section{Aplicações do esteatito}

Além da baixa dureza, a facilidade de extração estimulou o emprego da pedra-sabão na confecção de peças artesanais, como objetos de arte e utensílios culinários. Acredita-se que os indígenas que ocupavam a região do Sudeste do Brasil foram os primeiros 
indivíduos no continente sul-americano a usar a pedrasabão esculpida na forma de utensílio para o contato com alimentos [12].

Até hoje em determinadas cidades do Sudeste brasileiro, especialmente as próximas às jazidas de esteatito, como em Ouro Preto (MG, Brasil), é tradicional o emprego de utensílios confeccionados em pedra-sabão no preparo culinário de alimentos. Outro provável fator que influenciou nesta tradição, foi o clima da região que favorece temperaturas baixas especialmente à noite, uma vez que a pedra-sabão possui a característica de baixa condutância térmica, mantendo o alimento aquecido por longos períodos [12, 13].

A aplicação do esteatito como artesanato foi observada desde o século XVII. O nome "pedra-sabão" foi conferido à rocha pelos artistas da época barroca, dos quais o mais conhecido é Antônio Francisco Lisboa, o "Aleijadinho", devido à pequena dureza apresentada. Nas igrejas de Ouro Preto e em Congonhas (MG, Brasil), são encontradas diversas obras esculpidas em pedra-sabão, muitas das quais foram tombadas como patrimônio histórico mundial. $\mathrm{Na}$ atualidade, os produtos confeccionados em pedra-sabão vão desde utensílios, como as "panelas de pedra" até obras de arte, voltadas para o comércio local e para exportação $[2,12]$.

As panelas de pedra-sabão do modelo tradicional são encontradas na região de Ouro Preto (MG, Brasil) com bastante facilidade e a preço acessível ao consumidor, inclusive ao de baixa renda. Nos últimos anos foram lançadas no mercado panelas de diversos tamanhos e formatos, bem como modelos sofisticados do utensílio, como os que possuem cabo de cobre e mesmo de aço inoxidável, com apelo ao turista estrangeiro e ao consumidor nacional. Esta ampliação de mercado corresponde a uma expansão do universo de usuários que utilizam a panela de pedra no preparo de alimentos [13].

Por outro lado, o maior uso de panelas de pedra-sabão implica numa maior produção do recipiente. Apesar da industrialização verificada na maioria dos setores da economia mundial e também nacional, o processo de confecção da panela de pedra-sabão ainda é considerado como sendo quase que exclusivamente artesanal, pela própria natureza da matéria-prima [2].

\section{Utilização das panelas de pedra-sabão no preparo de alimentos}

O uso culinário dos utensílios de pedra-sabão é uma tradição ainda praticada por uma parcela considerável de habitantes da cidade de Ouro Preto (MG), localidade com 68.208 habitantes [22]. Levantamento sobre o uso doméstico da panela de pedra-sabão feito na área urbana da cidade de Ouro Preto por entrevista com 223 famílias nativas indicou que $81 \%$ dos domicílios têm panelas de pedra-sabão. Entre os que possuem o utensílio, 79\% declarou utilizá-lo três ou mais vezes por semana, sendo que os demais referiram usar de forma mais esporádica, incluindo em ocasiões festivas ou mesmo na forma de decoração de ambientes [14].

Assim, além das panelas de pedra-sabão serem fabricadas na região de Ouro Preto (MG), foi constado que as referidas panelas são utilizadas com regularidade por expressiva parcela da população local. Entre os pratos culinários elaborados neste utensílio, diversos foram mencionados, sendo o feijão, o arroz, a fritura de carne, o angu e o ensopado os principais pratos preparados nas panelas de pedra-sabão $[2,14]$.

A natureza antiaderente e a inércia térmica foram referidas como vantagens pelos usuários das panelas de pedra-sabão. Por outro lado, o peso e as freqüentes rachaduras se mostram como sendo seus principais limitantes. É conhecido que quanto maior o diâmetro do fundo do recipiente, maior a chance de que o mesmo apresente rachadura durante sua vida útil devido ao coeficiente de dilatação do esteatito [14].

Segundo os usuários, a prevenção das indesejáveis rachaduras, que limitam o tempo de vida útil da panela, é feita mediante o processo de cura do utensílio. Tal procedimento precede o primeiro uso do utensílio, quando a panela ainda é nova. A cura é um procedimento não padronizado que envolve sempre algum tipo de lipídio e calor [2].

Um dos maiores fabricantes de panelas de pedra-sabão recomenda que a cura seja feita da seguinte maneira: untar o utensílio interna e externamente com óleo vegetal comestível, encher o recipiente com água em temperatura ambiente, levar a panela ao forno que é aceso e mantido na temperatura de $200{ }^{\circ} \mathrm{C}$ por cerca de $2 \mathrm{~h}$. Decorrido este tempo o forno é desligado e as panelas retiradas somente quando completamente resfriadas, o que pode levar cerca de $10 \mathrm{~h}$ dada a inércia térmica do material. A conclusão do processo de cura ocorre após a repetição dos passos aqui descritos, estando, a seguir, a panela curada e pronta para ser usada no preparo de alimentos [14].

Entre a população usuária das panelas de pedra-sabão pôde ser verificado que a cura muitas vezes é feita com banha de porco ou manteiga, o calor empregado pode ser o gerado por forno convencional ou mesmo pelo sol, neste caso expondo o utensílio previamente untado à luz solar durante vários dias consecutivos. Os usuários também referem que eventualmente costumam curar novamente o utensílio durante a sua vida útil, embora não saibam expressar a periodicidade com que executam o procedimento. $\mathrm{O}$ fator predominante que leva à cura do material pelos usuários é decorrente exclusivamente da crença na prevenção de rachaduras no fundo do recipiente [13].

A cura do utensílio de pedra-sabão tem grande impacto sobre a perda de peso do material em função do uso. A avaliação da perda de peso por erosão do material indicou ser esta variável, sendo menor em panelas curadas em relação às não-curadas. Nas panelas não curadas a perda de peso pode chegar a $50 \mathrm{~g}$ após 18 cocções seqüênciais com ácido acético a $5 \%$. É provável 
que a menor corrosão observada nas panelas curadas se deva, ao menos em parte, à formação de uma película protetora nestes utensílios durante o tratamento térmico com lipídio (cura). A referida película poderia proteger o utensílio frente à corrosão promovida pelo ácido acético. Uma vez que os utensílios usados na forma crua não possuem esta proteção, consequentemente acabam estando sujeitos à maior erosão [13].

\section{Migração de metais de interesse nutricional do esteatito}

Os utensílios culinários de pedra-sabão, um dos primeiros materiais usados pelo homem para contato com alimentos, só foram estudados recentemente quanto às suas possíveis implicações nutricionais. Considerando que o esteatito é composto por um conjunto de determinados minerais, formados por vários elementos [1, 16-19], os estudos feitos consideraram a possibilidade de transferência destes para os alimentos $[1,2,10,13,14]$. Os principais minerais que compõem o esteatito contêm elementos de relevância nutricional como o cálcio, magnésio, ferro e manganês. Entretanto, contém também elementos de importância toxicológica como o níquel e o alumínio [13-19].

O conhecimento popular mineiro indicou há muito que o hábito de preparar os alimentos neste utensílio é um meio coadjuvante no tratamento da anemia ferropriva [2]. Tal crença aponta tanto para a ocorrência de migração do Fe contido na panela como também para uma certa biodisponibilidade do metal migrante.

Os dados sobre a migração de metais a partir de panelas de pedra-sabão foram inicialmente determinados por Quintaes, em 2000 [13]. A avaliação da migração de magnésio, cálcio, ferro, manganês, cobalto, alumínio, cromo e níquel, para um simulante de alimento preparado em duas concentrações (ácido acético a $3 \mathrm{e}$ $5 \%$ ) foi avaliado em ensaio laboratorial. Vinte cocções seqüenciais, cada uma com duração de 20 min contados a partir do momento de ebulição do simulante, foram realizadas em panelas de pedra-sabão novas, tanto in natura como curadas.

A migração dos elementos Co e Cr para o simulante de alimento, apresentou valor elevado somente nas duas primeiras cocções realizadas. A partir de então a migração de ambos elementos se manteve com valores desprezíveis. Comparativamente, a migração de $\mathrm{Cr}$ obtida a partir do esteatito $(0,01-0,05 \mathrm{mg} / \mathrm{L})$ [13] pôde ser considerada ligeiramente inferior à verificada por outros autores para os utensílios de inox, com níveis reportados entre 0,01 e $0,42 \mathrm{mg} / \mathrm{L}$, variando segundo o tipo de experimento e número de cocções $[9,11,23]$. Geralmente em utensílios de inox a migração de metais, incluindo o $\mathrm{Cr}$, ocorre de forma descendente. Os valores expressivos são observados somente nas primeiras três ou quatro vezes de uso, reduzindo a seguir para níveis mínimos $(0,01 \mathrm{mg} / \mathrm{L})[10,11,24]$.
Tabela I - Valores médios de migração (mg/L) de Ca, Mg, Fe e Mn a partir de panelas de pedra-sabão curadas e não-curadas, extraídos com ácido acético ( 3 e 5\%) mantido em ebulição por $20 \min [13]$.

[Table I - Average values of migration $(\mathrm{mg} / \mathrm{L})$ of $\mathrm{Ca}, \mathrm{Mg}, \mathrm{Fe}$ and Mn from cured and not-cured soapstone pans, extracted with acetic acid (3 and 5\%) kept in boiling for $20 \mathrm{~min}$ [13].]

\begin{tabular}{lccccc}
\hline \multirow{2}{*}{ Panelas } & \% acido & \multicolumn{4}{c}{ Metais migrantes (mg/L) } \\
& acético & $\mathrm{Ca}$ & $\mathrm{Mg}$ & $\mathrm{Fe}$ & $\mathrm{Mn}$ \\
\hline A (não-curada) & 5 & 97 & 45 & 16 & 3 \\
B (não-curada) & 5 & 1488 & 747 & 185 & 25 \\
Cb (não-curada) & 5 & 1288 & 646 & 146 & 21 \\
D (não-curada) & 3 & 209 & 232 & 69 & 4 \\
E (não-curada) & 3 & 326 & 291 & 70 & 6 \\
F (não-curada) & 3 & 856 & 450 & 94 & 13 \\
G (curada) & 5 & 120 & 89 & 22 & 2 \\
H (curada) & 5 & 485 & 294 & 60 & 8 \\
I (curada) & 5 & 108 & 58 & 15 & 3 \\
J (curada) & 3 & 88 & 68 & 17 & 2 \\
K (curada) & 3 & 99 & 73 & 17 & 2 \\
L (curada) & 3 & 151 & 73 & 22 & 2 \\
\hline
\end{tabular}

auso descontinuado após 12 ciclos; ${ }^{b}$ uso descontinuado após 18 ciclos.

A migração quantitativa dos elementos foi encontrada nesta ordem: $\mathrm{Ca}, \mathrm{Mg}$, Fe e $\mathrm{Mn}$, tendo sido notada grande variabilidade na migração, a qual foi atribuída à composição geoquímica intrínseca da rocha. A acidez do simulante mostrou influenciar fortemente a migração destes metais. Por outro lado, a cura do material mostrou ter um impacto negativo sobre a migração destes metais, embora mantendo a proporção e a ordem majoritária dos migrantes (Tabela I) [13].

Conforme pode ser observado na Tabela I, as panelas não-curadas apresentaram as maiores taxas médias de migração dos elementos $\mathrm{Ca}, \mathrm{Mg}, \mathrm{Fe}$ e $\mathrm{Mn}$ em relação às curadas. A erosão química das panelas não-curadas B e C foi tão extrema que ambas foram perfuradas na $13^{\mathrm{a}}$ e $19^{\mathrm{a}}$ repetição, respectivamente. A menor erosão observada nas panelas curadas fornece fundamento para o fato dos usuários destes utensílios executarem o procedimento de cura antes do seu primeiro uso [13].

Em outro estudo, pesquisadores determinaram em ensaio laboratorial a migração de metais $(\mathrm{Ca}, \mathrm{Mg}, \mathrm{Fe}, \mathrm{Mn}$, $\mathrm{Ni}$,), desta vez usando como extrator dois simulantes de alimentos, a saber: ácidos láctico e acético. O experimento contou com 15 cocções seqüenciais com cada ácido, realizadas em panelas novas de pedra-sabão curadas. Os autores verificaram que o ácido láctico extrai maiores teores dos metais em relação ao acético. Em função do uso, foi verificado que a migração global apresenta um declínio suave, com ambos extratores [10].

Estudo envolvendo a exposição dos utensílios de 
pedra-sabão ao aquecimento descontínuo de óleo de soja refinado, indicou que o $\mathrm{Fe}$ derivado deste material favorece a termoxidação lipídica. Neste ensaio os melhores materiais para a fritura de alimentos foram o vidro e o alumínio, e os piores a pedra-sabão seguida do inox e do ferro, nesta ordem, pela degradação que estes promoveram no óleo [25].

Assim, frente aos dados disponíveis pode ser referido que o uso regular da panela de pedra-sabão no preparo de alimentos pode promover uma contribuição na ingestão de nutrientes como $\mathrm{Ca}, \mathrm{Mg}, \mathrm{Fe}$ e $\mathrm{Mn}$, elementos tidos geralmente como carenciais. Os ensaios realizados com simulantes de alimentos indicaram que há transferência significativa de ferro do utensílio de pedra-sabão durante o processo de cocção. Neste contexto, a panela de pedra-sabão foi considerada como bom veículo de ferro, liberando teores superiores aos observados para alimentos ácidos e aquosos preparados em panelas de ferro $[2,5,10,13,26]$.

No entanto, as informações científicas disponíveis até o momento fornecem somente respaldo parcial ao conhecimento popular, que tem no uso da panela de pedrasabão uma forma de tratamento e profilaxia da anemia ferropriva $[2,13]$, uma vez que a biodisponibilidade destes elementos, incluindo o $\mathrm{Fe}$, ainda necessita ser avaliada. É interessante destacar que, em se tratando de panelas de ferro fundido, o $\mathrm{Fe}$ migrante possui biodisponibilidade similar a do ferro intrínseco dos alimentos vegetais $[5,8$, 26, 27]. Assim, é provável que o Fe derivado das panelas de pedra-sabão possua uma certa biodisponibilidade [2, $13]$.

Também permanece a necessidade de ser determinado o tempo em que a migração de ferro e dos demais elementos pode ser considerado representativo, uma vez que nos experimentos realizados com panelas curadas foi observada tendência à redução com o acréscimo no número de uso do utensílio, sendo o nível máximo atingido na décima cocção $[2,10,14]$.

\section{Migração de elementos com potencial efeito toxicológico do esteatito}

Em 2002 pesquisadores reportaram o teor de chumbo $(\mathrm{Pb})$ e cádmio $(\mathrm{Cd})$ a partir de panelas de pedra-sabão curadas e não-curadas, expostas à cocção com ácido acético [14]. Os níveis detectados destes metais estiveram sempre abaixo de $127 \mu \mathrm{g} / \mathrm{L}$, não representando toxidade ao homem $[30,31]$. Os menores teores foram verificados nos extratos oriundos das panelas curadas.

Também há referência para migração de $\mathrm{Pb}$ e $\mathrm{Cd}$ a partir de amostras de esteatito em condições laboratoriais em taxas inferiores a $100 \mu \mathrm{g} / \mathrm{L}$ [28]. Em outro laboratório foram identificadas taxas de arsênio, mercúrio, $\mathrm{Cd} \mathrm{e} \mathrm{Pb}$ abaixo de $100 \mu \mathrm{g} / \mathrm{L}$ [29]. Assim sendo, o utensílio de pedra-sabão pode ser considerado como seguro para o uso culinário segundo os parâmetros determinados pelo Food and Drug Administration (FDA), que estabelece um limite de segurança de $0,5 \mathrm{mg} / \mathrm{L}$ para migração de $\mathrm{Cd}$ e de $3,0 \mathrm{mg} / \mathrm{L}$ para o $\mathrm{Pb}[30,31]$.

Além destes metais, há outros de relevância toxicológica que podem estar presentes no esteatito. É sabido que rochas ultrabásicas, protólitos dos esteatitos, são usualmente enriquecidas em elementos como o níquel e cromo [15-17]. Processos de metamorfismo redistribuem estes elementos e os acomodam como novos minerais, quando estão em quantidades suficientes para o isolamento de fases cristalinas, ou os dispersam como substituições dentro de outros retículos que os aceitem [17]. Esta aceitação vai depender de raios iônicos, valências e compensações de carga. Minerais e candidatos a estas substituições são: cromo na titanita ocupando o sítio do titânio; níquel na serpentina substituindo o magnésio; níquel e cobalto substituindo o ferro na magnetita; níquel e cobalto substituindo ferro na pirita. O alumínio também pode ser encontrado como substituições do silício e do magnésio presentes no talco, além de estar presente em dois sítios como soluções sólidas na fórmula da clorita, sendo que sua variação pode alterar os parâmetros cristalinos do mineral [19, 20].

A avaliação da migração de $\mathrm{Al}$ a partir do esteatito para simulante de alimento indicou que os níveis são da ordem de 0 a $1,23 \mathrm{mg} / \mathrm{L}$ [13]. O limite de Ingestão Tolerável Provisória Semanal (PTWI - Provisional Tolerable Weekly Intake) estabelecido pela Organização Mundial da Saúde (OMS) para o Al é de $7 \mathrm{mg} / \mathrm{kg}$ de peso corporal [32]. Assim, com respeito à migração de alumínio, as panelas de pedra-sabão se mostram inócuas à saúde humana.

Por outro lado, a ocorrência de migração de $\mathrm{Ni}$ em nível tóxico se mostra factível quando a panela de pedra-sabão não sofre o processo de cura. Pesquisadores relataram valores entre 0,5 a $1,8 \mathrm{mg} / \mathrm{L}$, sendo que a migração Ni se mostrou mais elevada segundo a acidez do meio [14]. Tal migração não é surpreendente uma vez que o Ni é um dos componentes do esteatito [1720]. Pelo lado toxicológico, este elemento merece ênfase por ser considerado como um dos metais mais tóxicos da tabela periódica [9] sendo indesejável sua presença em alimentos [9, 33].

Em se tratando de panelas de pedra-sabão curadas, pesquisa aponta que os teores de migração de $\mathrm{Ni}$ extraídos durante a cocção de ácidos acético e láctico, não representam toxidade ao homem [10]. Neste caso a migração se mantém constantemente baixa, independente do número de cocções seqüenciais, tipo e concentração do meio de cocção $[10,14]$. O nível máximo de ingestão tolerada (UL) de níquel é de 1,0 mg/dia para indivíduos com quatorze ou mais anos de ambos os gêneros. Para crianças de um a três anos o UL é de $0,2 \mathrm{mg} / \mathrm{dia}$ e para aquelas com idade de 4 a 8 anos, $0,3 \mathrm{mg} / \mathrm{dia}$. O UL para indivíduos com idade entre 9 e 13 anos é de $0,6 \mathrm{mg} / \mathrm{dia}$ [34].

Todavia, a estocagem de ácido acético em panelas de 
pedra-sabão curadas, por cinco ciclos de $24 \mathrm{~h}$ cada, a $22{ }^{\circ} \mathrm{C}$ possibilitou a migração indesejável de $\mathrm{Ni}$, a qual pode chegar a $0,6 \mathrm{mg} / \mathrm{L}$ [10]. Assim, após o preparo de alimentos, especialmente aqueles ácidos e aquosos como sopas e molhos, é desaconselhável mantê-los em contato com o recipiente por período superior a $24 \mathrm{~h}$.

Apesar dos usuários das panelas de pedra-sabão realizarem o processo de cura regularmente nos utensílio novos somente visando à prevenção de rachaduras, os ensaios realizados até o momento constataram que a cura tem um papel importante na inibição da migração de Ni. Tal procedimento deve ser incentivado, pois sua necessidade é real sob o ponto de vista toxicológico [2, 14].

Um outro aspecto toxicológico importante relacionado aos utensílios de pedra-sabão diz respeito ao seu processo de fabricação artesanal. Recentemente pesquisadores averiguaram a ocorrência de talcose entre os artesões que manipulam o esteatito no Distrito de Mata dos Palmitos, em Ouro Preto (MG, Brasil). Além de avaliar o estado de saúde dos artesãos, os pesquisadores também determinaram a presença de asbestos na poeira proveniente da produção de artefatos artesanais de pedrasabão, especialmente na fase de polimento dos produtos. Os resultados do estudo indicaram que a produção de artefatos de pedra-sabão pode ter implicação importante no estado de saúde dos seus manipuladores [35]. Este estudo comprovou em humanos, o que anteriormente havia sido observado em ensaio toxicológico com ratos submetidos à inalação de talco por mais de 100 semanas consecutivas [36].

\section{Origem dos elementos migrantes}

A origem dos elementos migrantes e/ou de frações dos outros elementos no produto das cocções pode estar relacionada à solubilização de porções terminais dos minerais, rompidas mecanicamente durante a fabricação das panelas. As bordas fragmentadas de retículos apresentam redução na estabilidade química, especialmente nas partes periféricas, se comparadas às estruturas íntegras dos minerais [20]. Assim, a presença de $\mathrm{Al}$ e $\mathrm{Ni}$, principalmente nos extratos dos primeiros ciclos de cocção, pode estar relacionada às rupturas físicas dos cristais superficiais de talco com bordas danificadas.

Foi relatado que em se tratando de um mesmo tipo de utensílio (curado e não-curado) as curvas de migração específica dos elementos $\mathrm{Ca}, \mathrm{Mg}$, Fe e Mn apresentam, em diferentes escalas, um comportamento similar. Estatisticamente, a relação existente entre os principais elementos migrantes pôde ser mais bem compreendida pelo coeficiente de correlação de Pearson, que indica por um índice sem dimensão, situado entre $-1,0$ e 1,0, a extensão de uma correlação linear entre dois conjuntos de dados [13].

Conforme indicado na Tabela II, os valores
Tabela II - Coeficientes de correlação de Pearson entre elementos migrantes extraídos de panelas de pedra-sabão com simulante de alimento em duas concentrações (3 e 5\%) [13].

[Table II - Pearson's correlation coefficients of extracted elements from soapstone pans with food simulant in two concentrations (3 and 5\%) [13].]

\begin{tabular}{|c|c|c|c|}
\hline \multirow[b]{2}{*}{ Panelas e simulantes } & \multicolumn{3}{|c|}{$\begin{array}{c}\text { Coeficiente de correlação } \\
\text { entre elementos }\end{array}$} \\
\hline & $\mathrm{Ca} / \mathrm{Fe}$ & $\mathrm{Ca} / \mathrm{Mg}$ & $\mathrm{Ca} / \mathrm{Mn}$ \\
\hline $\begin{array}{l}\text { Curadas testada com } \\
\text { ácido acético } 5 \%\end{array}$ & 0,97 & 0,97 & 0,99 \\
\hline $\begin{array}{l}\text { Curadas testada com } \\
\text { ácido acético } 3 \%\end{array}$ & 0,83 & 0,83 & 0,92 \\
\hline $\begin{array}{l}\text { Não curadas testada } \\
\text { com ácido acético 5\% }\end{array}$ & 0,97 & 0,96 & 0,99 \\
\hline $\begin{array}{l}\text { Não curadas testada } \\
\text { com ácido acético 3\% }\end{array}$ & 0,86 & 0,91 & 0,89 \\
\hline
\end{tabular}

encontrados na correlação de Pearson mostraram uma associação positiva entre o $\mathrm{Ca}$, usado como variável independente, e os elementos $\mathrm{Fe}, \mathrm{Mg}$ e $\mathrm{Mn}$. Esta associação foi mais acentuada quando usado o simulante na forma mais concentrada (ácido acético a 5\%). Nesta Tabela também pode ser notado que o fato de se promover a cura da panela não mostrou ter influência alguma nesta correlação. O coeficiente de correlação de Pearson obtido indicou que a migração observada não ocorreu de forma independente, ou seja, os elementos migrantes se mostram interligados num mesmo componente mineral da rocha, o qual acaba sendo solubilizado no meio ácido com elevação da temperatura durante a cocção [13].

Entre os minerais que compõem o esteatito, apenas o carbonato dolomita possui simultaneamente $\mathrm{Ca}$ e $\mathrm{Mn}$ em sua estrutura química $\left[\mathrm{CaMg}\left(\mathrm{CO}_{3}\right)_{2}\right]$. Este mineral admite $\mathrm{Fe}$ e/ou $\mathrm{Mn}$ em substituição ao $\mathrm{M}^{2} \mathrm{~g}$ na sua fórmula estrutural [14, 37]. No esteatito presente no Quadrilátero Ferrífero brasileiro tem sido observada neste carbonato a razão de $\mathrm{Ca}: \mathrm{Mg}$ de 1:1, com valores insignificantes de $\mathrm{Mn}$ e $\mathrm{Fe}$ [15]. Em humanos, a ingestão de dolomita ocorre na forma de suplementos nutricionais de $\mathrm{Ca} e$ $\mathrm{Mg}$, os quais podem ser produzidos à base de dolomita. No entanto é necessário que o processo de purificação do carbonato seja feito adequadamente para evitar que metais indesejáveis como $\mathrm{Pb}, \mathrm{Hg}$ e outros presentes na matéria prima sejam veiculados no suplemento [38].

A migração majoritária de elementos da pedra-sabão para o simulante de alimento segue a composição possível da dolomita. Este mineral foi considerado como sendo o principal candidato para fonte dos elementos detectados nos ensaios laboratoriais com ácido acético [2, 10]. Esta observação foi ainda reforçada quando associada à característica química da dolomita, a qual é referida como apresentando boa solubilidade em meio ácido, 

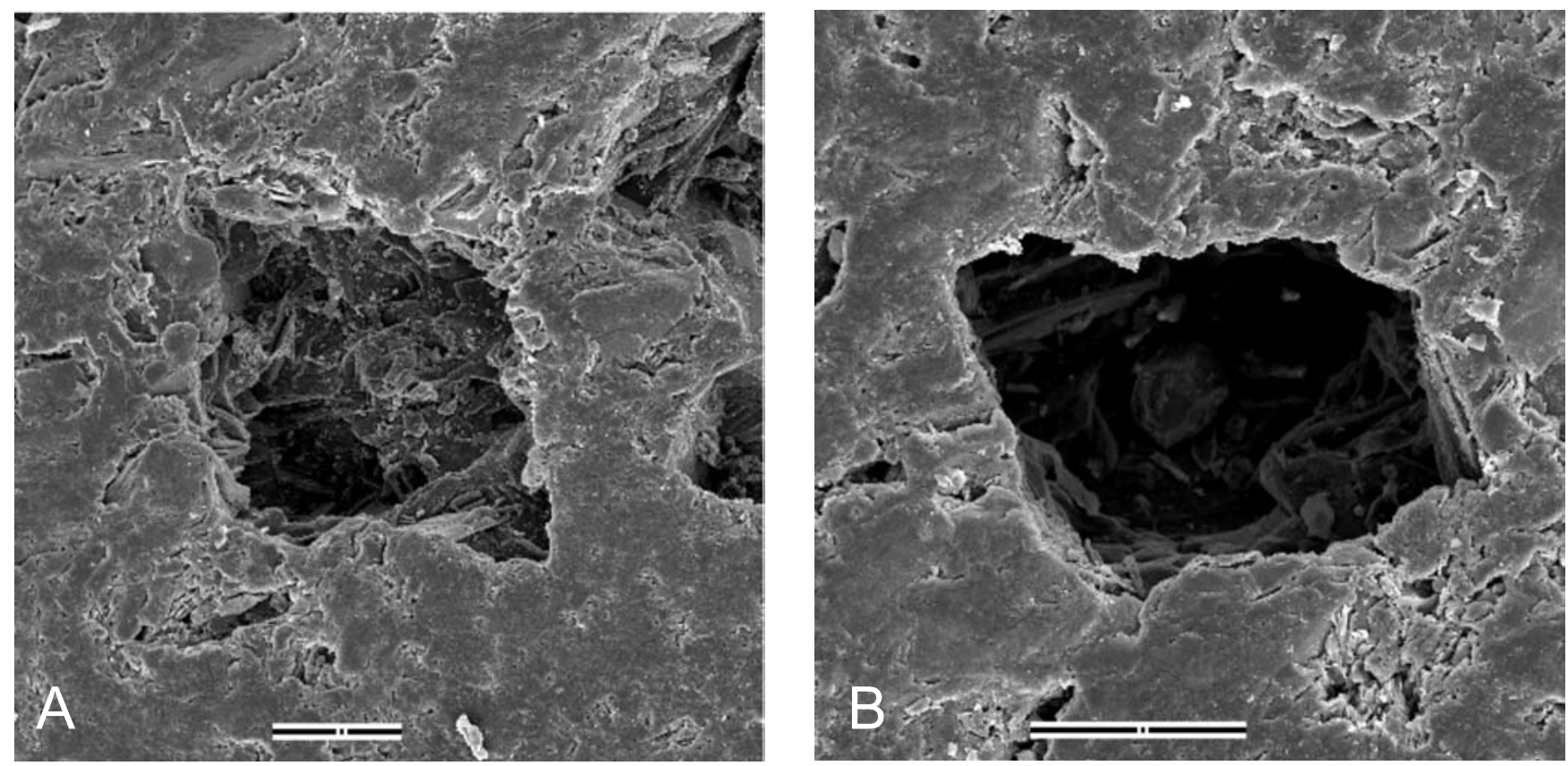

Figura 1: Imagens da superfície interna do fundo de panela de esteatito obtida por microscópio eletrônico de varredura (JEOL 840A), mostrando cavidade romboédrica resultante da dissolução de dolomita. A barra em escala equivale a 0,2 $\mathrm{mm}$.

[Figure 1: Images of deep internal surface of steatite pan gotten by electron microscope (JEOL 840A), showing rhombohedra socket as a result from dolomite dissolution. The bar in scale is equivalent to $0.2 \mathrm{~mm}$.]

especialmente com elevação de temperatura [20,39].

No sentido de garantir e confirmar a origem mineralógica dos elementos migrantes, análise por microscopia eletrônica de varredura das superfícies internas do fundo das panelas utilizadas no experimento com simulante de alimento (ácido acético a 5\%) foi efetuada em seqüência. Observou-se que as lamelas de talco do esteatito da panela se apresentavam com um alto grau de integridade. Por outro lado, foram constatadas cavidades de formato romboédrico [39], as quais podem ser observadas a seguir nas Fig. 1 (A e B).

É conhecido que dolomita é um mineral geológico que possui forma romboédrica [19, 38], formato similar ao observado nas imagens microscópicas das superfícies internas das panelas usadas nas cocções com ácido acético. Durante o processo de cocção do simulante, os cristais de dolomita estavam sendo corroídos ou completamente dissolvidos, deixando na rocha um espaço vazio, correspondente ao seu clássico formato físico [37]. Desta maneira pôde ser confirmado que a migração de metais em panelas de pedra-sabão se referem essencialmente à solubilização dos cristais de dolomita para o meio extrator.

Os orifícios deixados na superfície do material em função da dissolução da dolomita podem dificultar a higienização, ao mesmo tempo que podem servir de local de aderência de microrganismos e restos de alimentos. Esta possível conseqüência remete novamente à recomendação para não serem guardados alimentos nestes recipientes.

\section{CONCLUSÕES}

O esteatito provavelmente foi um dos primeiros materiais usados pelo homem para o contato com alimentos. No entanto, somente nos últimos anos suas possíveis implicações na saúde humana têm sido avaliadas. O processo de cura feito tradicionalmente pelos usuários antes do primeiro uso, além de prevenir rachaduras no material da panela, adiciona proteção às superfícies, reprimindo a migração de $\mathrm{Ni}$ e prevenindo a erosão química excessiva. Por outro lado, a estocagem de alimentos por período superior a $24 \mathrm{~h}$ é desaconselhável por favorecer a migração de $\mathrm{Ni}$, mesmo estando a panela devidamente curada. A cura permite transferência significativa de $\mathrm{Ca}, \mathrm{Mg}$, Fe e $\mathrm{Mn}$ para os meios de cocção, sendo uma prática recomendada.

Assim, o emprego de panelas curadas de esteatito no preparo de alimentos talvez possa refletir favoravelmente o estado nutricional dos consumidores. Entretanto a biodisponibilidade dos metais migrantes ainda está por ser estimada. Igualmente se faz necessário avaliar a migração destes metais durante a vida útil dos utensílios. Os dados atuais avaliaram o material até no máximo vinte cocções seqüenciais, o que corresponderia a no máximo três meses de uso regular do utensílio. Uma vez que os estudos realizados apontam para uma redução na migração com o aumento no número de exposições, é 
ainda necessário determinar até quando as quantidades dos metais liberados pelas panelas de pedra-sabão podem ser consideradas expressivas.

Do ponto de vista toxicológico foi comprovado em condições laboratoriais agressivas que o esteatito não libera metais pesados como $\mathrm{Pb}, \mathrm{Cd}$ e $\mathrm{Hg}$ em teores que representem toxidade ao homem. Por outro lado, ficou constatada a necessidade de um cuidado maior junto aos artesãos e indivíduos expostos à poeira advinda da manipulação do esteatito, uma vez que estas pessoas correm risco de desenvolver talcose, cujo efeito deletério à saúde é irreversível. Mais estudos são necessários sobre a relação entre o esteatito e a saúde humana.

\section{AGRADECIMENTOS}

Ao SAE/UNICAMP e ao CNPq pelo auxílio financeiro, a 'Ouro Preto Pedra Sabão' (OPPS) pelos laudos laboratoriais, e ao Prof. Dr. João Eduardo Addad pelo auxílio com a determinação geoquímica da dolomita.

\section{REFERÊNCIAS}

[1] R. O. Allen, K. K. Allen, C. G. Holland, W. W. Fitzhugh, Nature 271 (1978) 237.

[2] K. D. Quintaes, Tese de Doutorado, Universidade Estadual de Campinas, SP, Brasil (2004).

[3] F. H. Norton, Introdução à Tecnologia Cerâmica, Edgard Blücher e EDUSP, S. Paulo (1973).

[4] E. G. Rochow, Silicon and silicones: about stoneage tools, antique pottery, modern ceramics, computers, space, materials and how they all got that way, SpringVerlag, Berlim (1987).

[5] K. D. Quintaes, Rev. Nutr. 13 (2000) 151.

[6] M. Baxter, J. A. Burrell, R. C. Massey, Food Addit. Contam. 5 (1988) 651.

[7] J. A. T. Pennington, Food Addit. Contam. 5 (1987) 161.

[8] A. A. Adish, S. A. Esrey, T. W. Gyorkos, J. JeanBaptiste, A. Rojhani, Lancet 353 (1999) 712.

[9] J. Kuligowski, K. M. Halperin, Arch. Environ. Contam. Toxicol. 23 (1992) 211.

[10] K. D. Quintaes, J. Amaya-Farfan, F. M. Tomazini, M. A. Morgano, Ciênc Tecnol Alimen 24 (2004) 397.

[11] R. Kumar, P. K. Srivastava, S. P. Srivastava, Bull. Environ. Contam. Toxicol. 53 (1994) 259.

[12] M. E. Silva, Monografia de Conclusão de Curso, Universidade Federal de Ouro Preto, MG, Brasil (1997).

[13] K. D. Quintaes, Dissertação de Mestrado, Universidade Estadual de Campinas, SP, Brasil (2000).

[14] K. D. Quintaes, J. Amaya-Farfan, M. A. Morgano, D. M. B. Mantovani, Food Addit. Contam. 19 (2002) 134.

[15] H. Jordt-Evangelista, M. E. Silva, Rem, Rev. Esc. Minas 58 (2005): 11.

[16] H. Roeser, Anais do Congresso Brasileior de Geoquímica, Porto Alegre, RS (1987) 217-232.
[17] U. Roeser, H. Roeser, G. Mueller, H. J. Tobschall, Anais do XXXI Cong. Bras. Geol., Camburiú, SC, v. 4 (1980) 2230-45.

[18] M. Fleischer, J. A. Mandarino, Mineral species, Mineralogical Record Inc., Tucson (1995).

[19] W. A. Deer, R. A. Howie, J. Zussman, An Introduction to the Rock Forming Minerals, Longman Press, Essex (1966).

[20] V. Leinz, J. E. S. Campos, Guia para Determinação de Minerais, Companhia Editora Nacional, S. Paulo (1968).

[21] M. B. Perrin, An Introduction to the Chemistry of Rocks and Minerals. John Wiley \& Sons, New York (1975).

[22] Fundação IBGE, Censo demográfico (2000) http:// www.ibge.gov.br, acessado em Setembro de 2005.

[23] R. Brun, Contact Dermatite 5 (1979) 43.

[24] N. G. Flint, S. Packirisamy, Purity of food cooked in stainless steel utensils, Food Addit. Contam. 14 (1997) 115.

[25] K. Q. Quintaes, J. Amaya-Farfan, M. A. Morgano, N. M. A. Hajisa, Livro de Resumos do IX Taller Internacional sobre Calidad Sanitaria, Evaluacion Y Conservacion de Alimentos, Varadero, Cuba (2004).

[26] A. N. Mistry, H. C. Brittin, B. J. Stocker, Availability of iron from food cooked in an iron utensil determined by an in vitro method. J. Food Sci. 53 (1988) 1546.

[27] F. E. Martinez, H. Vannucchi, Nutr. Res. 6 (1986) 421.

[28] CIVO - Instituten TNO, Internal Technical Report of Contaminants Metals in Soapstone Cookware, Ontvangen (1989) $2 \mathrm{p}$.

[29] Politécnico di Torino. Internal Technical Report of Soapstone Cookware. Italy (1994) 3p.

[30] Food and Drug Administration, Action levels for poisonous or deleterious substances in human food and animal feed. http://www.vm.cfsan.fda.gov/ lrd/fdaact. html, acessado em Setembro 2005.

[31] W. M. Baczynskyj, N. J. Yess, J. AOAC Int. 78 (1995) 610.

[32] World Health Organization, Evaluation of Certain Food Additives and Contaminants, $33^{\text {rd }}$ Report of the Joint FAO/WHO Expert Committee on Food Additives, WHO Technical Report Series n. 776. WHO, Geneva (1989).

[33] G. A. Smart, J. C. Sherlock, Food Addit Contam. 4 (1987) 61.

[34] P. Trumbo, A. Y. Allison, S. Schlicker, M. Poos, J. Am. Diet. Ass. 101 (2001) 294.

[35] O. M. P. Bezerra, E. C. Dias, M. A. M. Galvão, A. P. S. Carneiro, Cad. Saúde Pública 19 (2003) 1751.

[36] National Toxicology Program. NTP Toxicology and Carcinogenesis Studies of Talc (CAS No. 1480796-6) (Non-Asbestiform) in F344/N Rats and B6C3F1 Mice (Inhalation Studies), National Toxicology Program Technical Report Serie 421 (1993) 287p.

[37] J. R. Goldsmith, D. L. Graf, J Geol 66 (1958) 678. 
[38] H. J. Roberts, South Med. J. 76 (1983) 556.

[39] K. D. Quintaes, J. Amaya-Farfan, M. A. Morgano,
D. M. B. Mantovani, J. E. Addad, Anais do IV Simp. LatAm Ci. Alim., Campinas, SP (2001).

(Rec. 03/04/2006, Ac. 04/08/2006) 